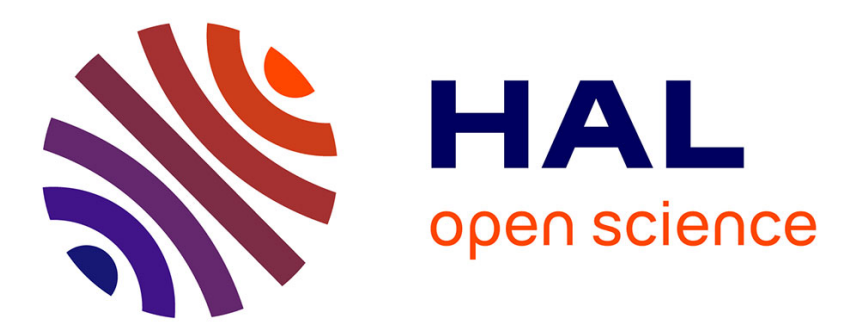

\title{
Temperature-related intraspecific variability in the behavioral manipulation of acanthocephalan parasites on their gammarid hosts.
}

Sophie Labaude, Frank Cézilly, Thierry Rigaud

\section{- To cite this version:}

Sophie Labaude, Frank Cézilly, Thierry Rigaud. Temperature-related intraspecific variability in the behavioral manipulation of acanthocephalan parasites on their gammarid hosts.. The Biological Bulletin, 2017, 232 (2), pp.82-90. 10.1086/692684 . hal-01575793

\author{
HAL Id: hal-01575793 \\ https://hal.science/hal-01575793
}

Submitted on 7 Jan 2022

HAL is a multi-disciplinary open access archive for the deposit and dissemination of scientific research documents, whether they are published or not. The documents may come from teaching and research institutions in France or abroad, or from public or private research centers.
L'archive ouverte pluridisciplinaire HAL, est destinée au dépôt et à la diffusion de documents scientifiques de niveau recherche, publiés ou non, émanant des établissements d'enseignement et de recherche français ou étrangers, des laboratoires publics ou privés. 
Keywords: parasite manipulation; temperature; anti-predatory behavior; gammarids;

11 acanthocephalan
Sophie Labaude*, Frank Cézilly, and Thierry Rigaud

Université de Bourgogne Franche-Comté, UMR CNRS 6282 Biogéosciences, Dijon, France

*Corresponding author: s.labaude@gmail.com 
12 Abstract. Understanding the effect of temperature on ecologically important species has

become a major challenge in the context of global warming. However, the consequences of climate change cannot be accurately predicted without taking into consideration biotic interactions. In particular, parasitic infection constitutes a widespread biotic interaction, and parasites impact their hosts in multiple ways, eventually leading to consequences on communities and ecosystems. Here, we explored the effect of temperature on the anti-predator behavior of a keystone freshwater invertebrate, the amphipod Gammarus fossarum.

Gammarids regularly harbor manipulative acanthocephalan parasites, which modify their antipredator behavior in ways that potentially increase the probability of trophic transmission to their definitive hosts. We investigated the impact of temperature on gammarids infected by two acanthocephalan parasites, Pomphorhynchus tereticollis and Polymorphus minutus. Uninfected and naturally infected gammarids were acclimatized to different temperatures, and their behavior was measured. Our results show that the effect of infection on the phototaxis of gammarids increased with increasing temperature, with a stronger effect induced by $P$. tereticollis. In contrast, temperature had no effect on the alteration of refuge use or geotaxis observed in infected gammarids. Our results provide the first direct evidence that temperature can affect the extent of behavioral alteration brought about by certain parasite species. However, the consequences in terms of increased trophic transmission remain elusive, as the supposedly key anti-predatory behavior was not significantly affected by exposure of gammarids to different temperatures. 
Although parasites have been ignored for decades in the field of ecology, they are now

widely recognized as important actors within ecosystems (Hudson et al., 2006; Lefèvre et al., 2009; Hatcher et al., 2012). Parasitic organisms might represent close to half of all biodiversity according to certain estimations (Poulin and Morand, 2000; Dobson et al., 2008), making parasitic infection one of the most common biotic interactions. Parasites have multiple impacts on their hosts that can have consequences on larger scales (Lefèvre et al., 2009; Hatcher et al., 2012). Differential pathogenic effects on several competing host species might for instance reverse the outcome of competition, or lead to the coexistence of species that would exclude each other in the absence of parasites (Hatcher et al., 2012). Parasites with complex life-cycles that rely on trophic transmission are particularly likely to affect many components of the ecosystems, as they are embedded in large food webs and have the potential to affect several host species in succession. In particular, some of these parasites are able to induce phenotypic changes in their intermediate hosts, supposed to increase the probability of predation by their definitive hosts, thus increasing their own probability of transmission (Poulin and Thomas, 1999; Moore, 2002). Many of these effects lead to deep changes in communities and ecosystems, such that these parasites are sometimes referred to as ecosystem engineers (Thomas et al., 1998, 1999; Sato et al., 2012).

In the current context of global change, understanding how environmental conditions might alter ecologically important species has become a major challenge, notably due to the necessity to make accurate predictions about the consequences of such changes. Taking into consideration biotic interactions, and in particular parasites, is therefore particularly important, especially considering that climate change might induce unpredictable consequences on both inter- and intra-specific interactions (Tylianakis et al., 2008; Rosenblatt and Schmitz, 2014). Temperature stands as a major parameter affecting many parasite-host 
systems (Marcogliese, 2001; Harvell et al., 2002; Barber et al., 2016), and it is likely that the impact of global change on ecologically important species might depend on the parasites that they harbor. In particular, the nature of the cumulative effect of parasitism and temperature on hosts, whether additive or interactive, is hardly predictable (Labaude et al., 2017).

Gammarids are widespread and abundant crustacean amphipods that are often seen as key species in freshwater ecosystems, where they constitute both important prey and predators for many species, modulating the composition of freshwater macroinvertebrates (Degani et al., 1987; Friberg et al., 1994; MacNeil et al., 1997; Kelly et al., 2002). They also play a major role in the maintenance of water quality through their roles as scavengers and shredders (MacNeil et al., 1997), in particular through the consumption of dead leaves (Piscart et al., 2009; Constable and Birkby, 2016). Gammarids are thus of significant ecological and economic importance as the quality of water is a key parameter in the emergence of waterborne diseases, ecosystem functioning, and maintenance of biodiversity (Klaphake et al., 2001).

Gammarids serve as intermediate hosts for several species of acanthocephalan parasites that use either birds or fish as definitive hosts. These parasites affect their gammarid hosts in multiple ways. In particular, acanthocephalan parasites can manipulate the behavior of gammarids in a way that appears to increase their probability of being predated by their definitive hosts (Lagrue et al., 2007; Perrot-Minnot et al., 2007; Dianne et al., 2011; but see Perrot-Minnot et al., 2012). Along with other impacts, such as alteration of food consumption (Fielding et al., 2003; Médoc et al., 2011; Labaude et al., 2017) or metabolic rate (Rumpus and Kennedy, 1974; Labaude et al., 2015a), such modifications might affect the role of gammarids within ecosystems.

Temperature affects several traits in the association between acanthocephalan parasites and their gammarid hosts. Both the time of development of parasites (Olson and Pratt, 1971; 
Tokeson and Holmes, 1982) and their success of establishment in their definitive fish host (Sheath et al., 2016) depend on temperature. On the other hand, temperature also affects the metabolism (Pöckl and Humpesch, 1990), growth (Moenickes et al., 2011), or consumption of gammarids (Foucreau et al., 2016), with potential effects on their interaction with parasites. In addition, the cumulative effect of acanthocephalan parasites and temperature on gammarids feeding behavior is dependent on gammarids’ aggregation context, with different consequences of the two parameters on the leave consumption of isolated individuals and individuals in groups (Labaude et al., 2017).

Temperature may also lead to variation in the rapidity or intensity of parasite manipulation (i.e. how parasites manipulate host behaviour in link with predation probability), whether directly or due to effects on other parameters, although only indirect evidence exists so far (reviewed in Labaude et al., 2015b). For instance, gammarids experimentally infected during winter were slower to display altered behaviors than gammarids infected in spring with the same parasite populations (Franceschi et al., 2010). Such result might arise from a positive effect of temperature on host and parasite metabolism. Following this hypothesis, higher temperature experienced by infected gammarids might also lead to stronger manipulation, in the case where such manipulation depends on host or parasite metabolism. Moreover, gammarids survival decreases at high temperatures (Maazouzi et al., 2011; Foucreau et al., 2014), and parasites would benefit in increasing their manipulating effort to secure their transmission (Thomas et al., 2002, 2011). Given the predicted increase of temperature in future years, improving our understanding of the consequences of temperature on hostparasite relationships is particularly relevant (Labaude et al., 2017).

Here, we tested the effect of exposure to different temperatures on the behavioral changes induced by two acanthocephalan species, the fish parasite Pomphorhynchus tereticollis and the bird parasite Polymorphus minutus, on their gammarid host Gammarus 
fossarum. These parasites manipulate different behaviors that are believed to be specific to the definitive host species (Tain et al., 2006). While P. tereticollis induces an inversion of the photophobic behavior of its intermediate host (Tain et al., 2006) and a decrease in its use of refuges (Perrot-Minnot et al., 2007), infection by P. minutus leads to reversed geotaxis, with gammarid individuals staying closer to the water surface than uninfected ones (Bauer et al., 2005). We relied on naturally infected gammarids with cystacanth parasites, the last larval stage that is infective for the definitive host and at which such changes occur in hosts, and investigated the effect of acclimatization at different temperatures on the behavior of uninfected and infected individuals.

\section{Sampling and acclimatization}

\section{Materials and Methods}

Gammarus fossarum individuals were collected in the Norges River (eastern France, 47²1'42.7"N 509'29.6"E, where gammarids are infected with P. tereticollis) in September 2015, and in the Vèze River (eastern France, 47¹4'01.9"N 5³4'37.4"E, where gammarids are infected with P. minutus) in June 2016, using a kick sampling method with a hand net. The Norges River only contains G. fossarum species (Lagrue et al., 2014; Labaude et al., 2017). Although Lagrue et al. (2014) found that more than half of gammarids from the Vèze River belonged to the closely-related G. pulex species, more recent genetic analyses performed on 457 individuals sampled in the Vèze River in May 2015 showed that about 90\% of them $(n=$ 410) belonged to G. fossarum (S. Labaude, unpublished data). Given the small proportion of G. pulex, and since the two cryptic species are often considered as a single taxonomic unit (Karaman and Pinkster, 1977), all individuals were used in this study. The brightly colored cystacanth stages of these parasites are visible through the cuticle of gammarids, allowing a 
preliminary selection of infected individuals directly in the field. Uninfected individuals were also captured.

Individuals from each population were randomly allocated to several groups that were acclimatized for 12 days in the laboratory at different temperatures. Individuals from the Norges River were acclimatized at three temperatures $\left(10,14\right.$, or $\left.18^{\circ} \mathrm{C}\right)$, whereas individuals from the Vèze River were separated into only two groups $\left(14\right.$ or $\left.18^{\circ} \mathrm{C}\right)$, due to sampling limitations resulting from the low prevalence of infection with $P$. minutus. Temperatures were chosen to be in accordance with naturally fluctuating temperatures experienced by gammarids in their habitat (Pöckl et al., 2003), and fell within the range of temperatures measured within the two rivers in 2015 (S. Labaude, personal data). To limit stress, individuals were maintained together in groups at each temperature, in an oxygenated mix of water collected in their river and dechlorinated, UV-treated tap water. They were fed ad libitum with conditioned elm leaves, and maintained under a 12:12 light:dark cycle regime. Due to different technical requirements associated with the behavioral tests, water temperature was controlled in two different ways. Because individuals had to be visible from above during behavioral tests (see below), individuals from the Norges River were maintained in water baths, following Labaude et al. (2017). Boxes containing individuals (and further test devices) were plunged into water that was constantly pumped through a temperature control device (TANK TK-1000 Chiller, Teco US). Individuals from the Vèze River, which were tested in vertical devices, were maintained and tested in refrigerators with transparent doors (Liebherr FKv 5443). These two systems allowed acclimatization and experiments for each population at all temperatures to occur concomitantly in the same room. The water temperature was controlled daily using digital thermometers. 
Norges River were used for phototaxis tests and, among them, 176 individuals (76 infected and 100 controls) were randomly chosen to be tested for refuge use. The two sets of experiments were conducted during the same day.

After the acclimatization period to different temperatures, single individuals were introduced into horizontal glass tubes (22 cm long, $3.2 \mathrm{~cm}$ diameter) containing a dark zone (half of the tube being covered with black plastic to ensure complete opacity) and a light zone, following the design described in Perrot-Minnot (2004). Tubes were previously filled with aerated water. Water temperature was maintained during the course of the experiment with the same device as described for acclimatization. After 5 min of habituation in the tube, the position of every individual was recorded every 30 s during 5 min and scored as zero (dark zone) or one (light zone). Summed phototaxis scores for each individual ranged from zero (strongly photophobic, always in the dark zone) to 11 (strongly photophilic, always in the light zone).

To test for the use of refuges, single individuals were placed in boxes $(10.5 \times 16 \mathrm{~cm})$ filled with $250 \mathrm{ml}$ of oxygenated water with temperature controlled for each group as previously described. A refuge was available in each box, consisting of a saucer terracotta pot (8.5 cm of diameter) cut in half, with a 1-cm hole in the convex part (see Dianne et al., 2014). After 5 min of habituation in the device following the introduction of gammarids, the position of each individual was recorded every 2 min during a 30-min observation period, and scored as zero (outside the refuge) or one (inside the refuge). Summed refuge scores ranged from zero (always outside the refuge) to 16 (always inside) for each individual.

For the two tests, a random number was assigned to each individual in order to ensure that the experimenter was unaware of the infection status of individuals. 
In total, 51 individuals infected by $P$. minutus and 59 uninfected individuals from the

Vèze River were used for geotaxis tests.

Geotaxis, the response of individuals to gravity, was estimated as the average vertical

\section{Measurements and dissections}

At the end of the experiment, the sex of each individual was determined using the size and shape of its first and second pairs of gnathopods, which are sexually dimorphic in amphipods (Hume et al., 2005). All individuals were measured (height of the fourth coxal plate) using a Nikon ZMZ1500 dissecting microscope and Lucia G 4.81 software, and dissected. The developmental stage (acanthella or cystacanth) and the species of parasites 
found within gammarids were determined based on morphological identification. As manipulation of the parasite depends on both acanthocephalan species and developmental stage, only individuals harboring $P$. tereticollis (for phototaxis and refuge use tests) and $P$. minutus (for geotaxis tests) parasites at the cystacanth stage were kept (hereafter referred as "parasitized" individuals). Individuals harboring other acanthocephalan species (a few Pomphorhynchus laevis and Echinorhynchus truttae were found), or acanthella stages were discarded. Gammarids in which no parasite could be found were considered as "control" individuals.

\section{Data analyses}

None of the three scores (phototaxis scores, refuge scores, and geotaxis scores) met normality and homoscedasticity conditions, even after data transformation. We therefore used non-parametric statistics. In both populations, the size of gammarids did not differ between parasitized and control individuals (data not shown), and was thus not considered in subsequent analyses. Comparisons between males and females for each infection status and at each temperature showed that there was no difference in the scores of individuals, for the three behaviors tested (data not shown). Therefore, sex was not considered in subsequent analyses.

First, the effect of temperature on each score was assessed using Kruskal-Wallis tests. The effect size of the differences between each temperature was then calculated for each score and for each infection status (control or parasitized) using Cliff's delta (Cliff, 1996). Cliff's delta was also used to compare the scores between control and parasitized individuals, at each temperature. Cliff's delta is a scale-less parameter, ranging from -1 to 1 , that is robust to nonnormally distributed data. It is used to represent the size of the effect, in this case the 
difference between two groups, as well as the direction of this difference. Moreover, its confidence intervals can be used to assess the significance between these differences, replacing classical statistic tests or post hoc tests. Medians and 95\% confidence intervals of the Cliff's delta were calculated using the R-package ‘orddom’ (version 3.1). Other statistical analyses were performed using R version 3.1.1 software (R Foundation for Statistical Computing).

\section{Results}

Temperature significantly affected the amount of time spent in light ("phototaxis score”) of G. fossarum individuals infected by P. tereticollis (Kruskal-Wallis, $\chi_{2}=22.86$, d.f. $=2, P<0.0001$, Fig. 1 A), and control individuals (Kruskal-Wallis, $\chi_{2}=23.30$, d.f. $=2, P<$ 0.0001 , Fig. $1 \mathrm{~A}$ ). The phototaxis score was significantly higher at $14^{\circ} \mathrm{C}$ and $18^{\circ} \mathrm{C}$ compared to $10^{\circ} \mathrm{C}$, in both parasitized and control individuals (Fig. 2A). However, while there was a clear trend for phototaxis score to increase with temperature between $14^{\circ} \mathrm{C}$ and $18^{\circ} \mathrm{C}$ for parasitized individuals, that of control individuals did not differ significantly between these two temperatures (Fig. 2A), with even a trend to decrease. As a result, the difference of behavior between control and parasitized individuals was significant at $14^{\circ} \mathrm{C}$ and $18^{\circ} \mathrm{C}$, with a stronger effect at $18^{\circ} \mathrm{C}$ (Fig. 2B).

Temperature had no effect on the amount of time spent inside refuges ("refuge score”) for both control individuals (Kruskal-Wallis, $\chi_{2}=0.57$, d.f. $=2, P=0.75$, Fig. $1 \mathrm{~B}$ ) and infected ones (Kruskal-Wallis, $\chi_{2}=1.83$, d.f. $=2, P=0.40$, Fig. $1 \mathrm{~B}$ ). The refuge score of individuals infected by P. tereticollis was lower than that of controls (Fig. 1B), illustrating a lower trend to use refuges, although this difference was significant only at $18^{\circ} \mathrm{C}$ (Fig. 2B). 
The non-significant differences were probably due to high inter-individual variation relative to the small sample size.

Correlations between phototaxis scores and refuge scores were all non-significant. The only trend observed was a negative correlation in parasitized individuals at $18^{\circ} \mathrm{C}$ (Table 1), with the more photophilic animals spending also more time out of refuges.

The geotaxis score of $G$. fossarum individuals infected by $P$. minutus was significantly higher than the score of control individuals (Fig. 3 and Fig 2B). Geotaxis scores were not influenced by temperature, with no difference between the two temperatures tested for both parasitized and control individuals (Fig. 3 and Fig 2).

\section{Discussion}

The temperature at which Gammarus fossarum were exposed for two weeks affected the intensity of phototaxis of $G$. fossarum, particularly in those infected with Pomphorhynchus tereticollis parasites. However, it had no impact on the time spent by gammarids inside refuges, independently of infection. No effect of temperature was found on gammarids geotaxis, whether infected or not by Polymorphus minutus parasites.

The differences in phototaxis observed between infected and control individuals across the three temperature tested here suggest that parasite manipulation was less efficient at low temperatures. Although both infected and uninfected animals were photophobic at low temperature, a gradual reversal of photophobia was observed in infected individuals at higher temperature, while this phenomenon stabilized in control individuals at the highest temperature. The increase in the manipulation of gammarids by $P$. tereticollis might be due to a physiological effect of temperature. Indeed, the metabolism of ectotherm species increases 
with temperature (Gillooly et al., 2001), including in acanthocephalan parasites which develop faster at high temperature (Olson and Pratt, 1971; Tokeson and Holmes, 1982). Thus, if the manipulation of host behavior is influenced by the physiology of parasites, it is possible that increased temperatures led to more pronounced manipulation. However, such a phenomenon hardly does not explain the increased phototaxis also observed in uninfected individuals between $10^{\circ} \mathrm{C}$ and $14^{\circ} \mathrm{C}$. The differences in phototactic behavior observed at different temperatures might instead stem from the mechanisms underlying this behavior. Serotonin plays a major role in the expression of phototactic behavior in gammarids: Pomphorhynchus parasites increase the brain serotoninergic activity of gammarids (Tain et al., 2006, 2007), and experimental injection of serotonin in uninfected individuals mimics the behavioral changes induced by parasites (Perrot-Minnot et al., 2014). The mechanisms by which acanthocephalans induce modifications in gammarids serotoninergic activity are unknown (Lafferty and Shaw, 2013). However, serotonin production increases with increased temperatures in invertebrates (Stefano and Catapane, 1977; Stefano et al., 1977), as well as many visual neural processes in invertebrates (Lim-Kessler et al., 2008). These changes are associated with modifications of other neuromodulators (Stefano and Catapane, 1977; Stefano et al., 1977), such that the consequences of these modifications can hardly be predictable. However, an increase in serotonin levels could explain the increase of phototaxis between the lowest temperature and the highest temperatures in our study, including in uninfected gammarids. It is possible that in infected individuals, the level of serotonin due to increased temperature and parasitic infection combine in the gammarid's brain to produce a higher photophilic response. Serotonin levels were not measured here. Therefore, since the invertebrate nervous system has a number of mechanisms designed to maintain homeostatic function despite the temperature-driven changes (Lim-Kessler et al., 2008) further studies are 
needed to explore the mechanisms of the link between temperature, acanthocephalan parasites and photophily in gammarids, in order to verify this hypothesis.

Although variations in serotonin levels explain variations in the phototaxis behavior of gammarids, they have no significant effect on the gammarids' ability to use refuges (PerrotMinnot et al., 2014). This may explain the absence of significant effect of temperature on this trait in our study, and the lack of correlation between these two behaviors. Similarly, the manipulation of $G$. fossarum by $P$. minutus, in terms of geotaxis, was not affected by temperature, although the lowest temperature was not tested. However, the alteration of geotaxis may not rely on the same mechanisms as the ones involved in the alteration of phototaxis. Indeed, Tain et al. (2006) showed that the geotaxis of gammarids was not affected by experimental injections of serotonin, and that infection by $P$. minutus did not induce modifications in the serotoninergic activity of gammarids. A recent study suggested a role of anaerobic metabolism and hypoxia in the manipulation induced by P. minutus: uninfected Gammarus roeseli displayed a negative geotaxis under hypoxia, while an injection of lactate and succinate in uninfected gammarids also mimicked the parasite-induced reversion of geotaxis (Perrot-Minnot et al., 2015). It would be interesting to test the effect of temperature variations large enough to induce higher changes in the amount of oxygen dissolved in the water. If this were the mechanism, we would expect the geotaxis of both infected and uninfected individuals to increase at high temperatures.

Overall, our study suggests that temperature might be responsible for variations in the efficiency of the manipulation of certain behaviors of gammarids by acanthocephalans. In particular, the global increase of temperature might induce a higher efficiency of manipulation by some parasites, while other aspects of manipulation, or behavioral changes in other species, might not be affected. Some of our results are in line with those obtained by Benesh et al. (2009) in isopods. They found that, whereas the intensity of phenotypic changes induced 
by the acanthocephalan Acanthocephalus lucii varied between seasons, experimental exposure to different temperatures did not change the intensity of manipulation of host behavior. Our study shows that some components of parasite-induced behavioral changes may be affected by temperature variation. Although the metabolism of acanthocephalan parasites is highly dependent on temperature, thus resulting in longer developmental time during cold periods (Olson and Pratt, 1971; Tokeson and Holmes, 1982), variations in the rapidity of their transmission to the next host might also arise from differences in their manipulation and partly explain the seasonal distribution documented in some acanthocephalan parasites (Van Cleave, 1916; Muzzall and Rabalais, 1975; Brown, 1989).

Parasites have numerous effects on communities and ecosystems, especially through the manipulation of the behaviour of their hosts (see Lefèvre et al., 2009; Labaude et al., 2015b for reviews). Consequently, modifications in manipulation following changes in temperature are also likely to have consequences at larger scales. In particular, acanthocephalan parasites are responsible for many modifications in the ecology of gammarids, including their feeding behaviour or microhabitat choice (Labaude et al., 2017; MacNeil et al., 2003). More to the point, an increase in the predation facilitation induced by parasites in response to increasing temperature might affect food webs, through alteration in the interaction between gammarids and their predators, as well as the dynamics of the populations of parasites, hosts and their predators. However, further studies are needed to determine the effect of temperature on the ecological outcome of manipulation, i.e. its effects in terms of predation facilitation induced by parasites. Indeed, although infected gammarids are more predated by the definitive hosts of parasites than uninfected ones (Bethel and Holmes, 1977; Perrot-Minnot et al., 2007; Jacquin et al., 2014), only certain behavioral changes have been demonstrated to be linked to this predation enhancement. More precisely, in gammarids, the presence of refuges and the intensity of their use was directly linked to 
differences in predation rate of gammarids infected by Pomphorhynchus parasites vs. uninfected ones (Kaldonski et al., 2007; Dianne et al., 2011, respectively), while the intensity of change in phototaxis was not (Perrot-Minnot et al., 2012). Similarly, the reversed geotaxis behavior was responsible for an increased predation in gammarids infected by Polymorphus parasites (Jacquin et al., 2014). Here, it is worth noting that the only behavior affected by temperature is the one for which no causal link with predation enhancement could be established. However, many other parameters might interact in the success of predation. In particular, the behavior of gammarids depends on predation risk (Médoc et al., 2009; Durieux et al., 2012; Lewis et al., 2012), while temperature might also alter the behavior of predators themselves (Brett, 1971; Elliott, 1976). In addition, temperature is likely to affect other parameters, such as the reproduction of parasites (Barber et al., 2016), leading to modifications in the population dynamics of both hosts and parasites that are hardly predictable. Finally, we did not control the environmental conditions during the development of parasites, and this can lead to other sources of variability. For instance, acanthocephalans develop faster at high temperatures (Olson and Pratt, 1971; Tokeson and Holmes, 1982), and the efficiency of their manipulation increases with time after they reached the cystacanth stage (Franceschi et al., 2008; Labaude et al., 2015a). Thus, it cannot be discounted that, in our experiments involving naturally-infected gammarids, those maintained at $18^{\circ} \mathrm{C}$ harbored parasites that already reached their highest manipulative intensity, while the manipulative intensity of gammarids kept at lower temperatures was still increasing. In addition, gammarid metabolism increases with temperature to a certain extent (Roux and Roux, 1967; Pöckl and Humpesch, 1990; Issartel et al., 2005), along with their mortality (Maazouzi et al., 2011; Foucreau et al., 2014). As parasites completely depend on the survival of their hosts before transmission, they would benefit in increasing their manipulating effort when the life expectancy of their hosts decreases to secure their transmission (Thomas et al., 2002, 2011). 
373 Consistent with this hypothesis, Poulin (1993) found that the intensity of behavioral changes

374 induced by trematode parasites was greater when their intermediate fish hosts were older.

375 However, contradicting with this hypothesis, no significant changes in refuge use were

376 observed in G. pulex infected with P. laevis under different survival conditions (Labaude et

377 al., 2015a). Future studies might therefore benefit from investigating the effect of temperature

378 using experimental infestations, to control for environmental conditions during the

379 development of the parasites.

\section{Acknowledgements}

We thank the ANR (Grant ANR-13-BSV7-0004-01) for financial support. SL was supported by a Doctoral grant from the Ministère de l'Education Nationale, de l'Enseignement their helpful comments.

\section{Literature Cited}

Barber, I., B. W. Berkhout, and I. Zalina. 2016. Thermal change and the dynamics of multi-host parasite life cycles in aquatic ecosystems. Integr. Comp. Biol. 56: 561-572.

Bauer, A., E. R. Haine, M.-J. Perrot-Minnot, and T. Rigaud. 2005. The acanthocephalan

Benesh, D. P., T. Hasu, O. Seppälä, and E. T. Valtonen. 2009. Seasonal changes in host 
136: 219-230.

397

398

399

400

401

402

403

404

405

406

407

408

409

410

411

412

413

414

415

416

417

418

Bethel, W. M., and J. C. Holmes. 1977. Increased vulnerability of amphipods to predation owing to altered behavior induced by larval acanthocephalans. Can. J. Zool. 55: 110115.

Brett, J. R. 1971. Energetic responses of salmon to temperature. A study of some thermal relations in the physiology and freshwater ecology of sockeye salmon (Oncorhynchus nerka). Am. Zool. 113: 99-113.

Brown, A. F. 1989. Seasonal dynamics of the acanthocephalan Pomphorhynchus laevis (Muller, 1776) in its intermediate and preferred definitive hosts. J. Fish Biol. 34: 183194.

Cliff, N. 1996. Ordinal Methods for Behavioral Data Analysis. Lawrence Erlbaum Associates, Inc., Majwaj, New Jersey.

Constable, D., and N. J. Birkby. 2016. The impact of the invasive amphipod Dikerogammarus haemobaphes on leaf litter processing in UK rivers. Aquat. Ecol. 50: 273-281.

Degani, G., H. J. Bromley, R. Ortal, Y. Netzer, and N. Harari. 1987. Diets of rainbow trout (Salmo gairdneri) in a thermally constant stream. Vie Milieu 37: 99-103.

Dianne, L., M.-J. Perrot-Minnot, A. Bauer, M. Gaillard, E. Léger, and T. Rigaud. 2011. Protection first then facilitation: a manipulative parasite modulates the vulnerability to predation of its intermediate host according to its own developmental stage. Evolution 65: 2692-2698.

Dianne, L., M.-J. Perrot-Minnot, A. Bauer, A. Guvenatam, and T. Rigaud. 2014. Parasite-induced alteration of plastic response to predation threat: increased refuge use 
but lower food intake in Gammarus pulex infected with the acanothocephalan Pomphorhynchus laevis. Int. J. Parasitol. 44: 211-216.

Dobson, A. P., K. D. Lafferty, A. M. Kuris, R. F. Hechinger, and W. Jetz. 2008. Homage to Linnaeus: how many parasites? How many hosts? Proc. Natl. Acad. Sci. U. S. A. 105: 11482-11489.

Durieux, R., T. Rigaud, and V. Médoc. 2012. Parasite-induced suppression of aggregation under predation risk in a freshwater amphipod. Sociality of infected amphipods. Behav. Processes 91: 207-213.

Elliott, J. M. 1976. The energetics of feeding, metabolism and growth of brown trout (Salmo trutta L.) in relation to body weight, water temperature and ration size. J. Anim. Ecol. 45: 923-948.

Fielding, N. J., C. MacNeil, J. T. A. Dick, R. W. Elwood, G. E. Riddell, and A. M. Dunn. 2003. Effects of the acanthocephalan parasite Echinorhynchus truttae on the feeding ecology of Gammarus pulex (Crustacea: Amphipoda). J. Zool. 261: 321-325.

Foucreau, N., D. Cottin, C. Piscart, and F. Hervant. 2014. Physiological and metabolic responses to rising temperature in Gammarus pulex (Crustacea) populations living under continental or Mediterranean climates. Comp. Biochem. Physiol. 168A: 69-75.

Foucreau, N., C. Piscart, S. Puijalon, and F. Hervant. 2016. Effects of rising temperature on a functional process: consumption and digestion of leaf litter by a freshwater shredder. Fundam. Appl. Limnol. / Arch. für Hydrobiol. 187: 295-306.

Franceschi, N., A. Bauer, L. Bollache, and T. Rigaud. 2008. The effects of parasite age and intensity on variability in acanthocephalan-induced behavioural manipulation. Int. J. Parasitol. 38: 1161-1170. 
Franceschi, N., L. Bollache, S. Cornet, A. Bauer, S. Motreuil, and T. Rigaud. 2010. Covariation between the intensity of behavioural manipulation and parasite development time in an acanthocephalan-amphipod system. J. Evol. Biol. 23: 2143-2150.

Friberg, N., T. H. Andersen, H. Hansen, T. M. Iversen, D. Jacobsen, L. Krojgaard, and S. E. Larsen. 1994. The effect of brown trout (Salmo trutta L.) on stream invertebrate drift, with special reference to Gammarus pulex L. Hydrobiologia 294: 105-110.

Gillooly, J. F., J. H. Brown, G. B. West, V. B. Savage, and E. L. Charnov. 2001. Effects of size and temperature on metabolic rate. Science 293: 2248-2251.

Harvell, C. D., C. E. Mitchell, J. R. Ward, S. Altizer, A. P. Dobson, R. S. Ostfeld, and M. D. Samuel. 2002. Climate warming and disease risks for terrestrial and marine biota. Science 296: 2158-2162.

Hatcher, M. J., J. T. A. Dick, and A. M. Dunn. 2012. Diverse effects of parasites in ecosystems: linking interdependent processes. Front. Ecol. Environ. 10: 186-194.

Hudson, P. J., A. P. Dobson, and K. D. Lafferty. 2006. Is a healthy ecosystem one that is rich in parasites? Trends Ecol. Evol. 21: 381-385.

Hume, K. D., R. W. Elwood, J. T. A. Dick, and J. Morrison. 2005. Sexual dimorphism in amphipods: the role of male posterior gnathopods revealed in Gammarus pulex. Behav. Ecol. Sociobiol. 58: 264-269.

Issartel, J., F. Hervant, Y. Voituron, D. Renault, and P. Vernon. 2005. Behavioural, ventilatory and respiratory responses of epigean and hypogean crustaceans to different temperatures. Comp. Biochem. Physiol. A. Mol. Integr. Physiol. 141: 1-7.

Jacquin, L., Q. Mori, M. Pause, M. Steffen, and V. Medoc. 2014. Non-specific manipulation of gammarid behaviour by $P$. minutus parasite enhances their predation by 
definitive bird hosts. PLoS ONE 9: e101684.

Kaldonski, N., M.-J. Perrot-Minnot, and F. Cézilly. 2007. Differential influence of two acanthocephalan parasites on the antipredator behaviour of their common intermediate host. Anim. Behav. 74: 1311-1317.

Karaman, G. S., and S. Pinkster. 1977. Freshwater Gammarus species from Europe, North Africa and adjacent regions of Asia (Crustacea-Amphipoda) Part I. Gammarus pulexgroup and related species. Bijdr. tot Dierkd. 47: 1-97.

Kelly, D. W., J. T. A. Dick, and W. I. Montgomery. 2002. The functional role of Gammarus (Crustacea, Amphipoda): shredders, predators, or both? Hydrobiologia 485: 199-203.

Klaphake, A., W. Scheumann, and R. Schliep. 2001. Biodiversity and International Water Policy. Institute for Management in Environmental Planning, Technical University of Berlin, Germany.

Labaude, S., F. Cézilly, X. Tercier, and T. Rigaud. 2015a. Influence of host nutritional condition on post-infection traits in the association between the manipulative acanthocephalan Pomphorhynchus laevis and the amphipod Gammarus pulex. Parasit. Vectors 8: 403.

Labaude, S., T. Rigaud, and F. Cézilly. 2015b. Host manipulation in the face of environmental changes: Ecological consequences. Int. J. Parasitol. Parasites Wildl. 4: 442-451.

Labaude, S., T. Rigaud, and F. Cézilly. 2017. Additive effects of temperature and infection with an acanthocephalan parasite on the shredding activity of Gammarus fossarum (Crustacea: Amphipoda): the importance of social context. Glob. Chang. Biol. 23: 1415- 
1424.

489

490

491

492

493

494

495

496

497

498

499

500

501

502

503

504

505

506

507

508

509

510

Lafferty, K. D., and J. C. Shaw. 2013. Comparing mechanisms of host manipulation across host and parasite taxa. J. Exp. Biol. 216: 56-66.

Lagrue, C., N. Kaldonski, M.-J. Perrot-Minnot, S. Motreuil, and L. Bollache. 2007. Modification of hosts’ behavior by a parasite: field evidence for adaptive manipulation. Ecology 88: 2839-2847.

Lagrue, C., R. Wattier, M. Galipaud, Z. Gauthey, J.-P. Rullmann, C. Dubreuil, T. Rigaud, and L. Bollache. 2014. Confrontation of cryptic diversity and mate discrimination within Gammarus pulex and Gammarus fossarum species complexes. Freshw. Biol. 59: 2555-2570.

Lefèvre, T., C. Lebarbenchon, M. Gauthier-Clerc, D. Missé, R. Poulin, and F. Thomas. 2009. The ecological significance of manipulative parasites. Trends Ecol. Evol. 24: 4148.

Lewis, S. E., A. Hodel, T. Sturdy, R. Todd, and C. Weigl. 2012. Impact of acanthocephalan parasites on aggregation behavior of amphipods (Gammarus pseudolimnaeus). Behav. Processes 91: 159-163.

Lim-Kessler, C.C.M., A.R. Bolbecker, J. Li, and G.S. Wasserman. 2008. Visual efference in Limulus: In vitro temperature-dependent neuromodulation of photoreceptor potential timing by octopamine and substance P. Visual Nerosci. 25: 83-94.

Maazouzi, C., C. Piscart, F. Legier, and F. Hervant. 2011. Ecophysiological responses to temperature of the "killer shrimp” Dikerogammarus villosus: is the invader really stronger than the native Gammarus pulex? Comp. Biochem. Physiol. 159A: 268-274.

MacNeil, C., J. T. A. Dick, and R. W. Elwood. 1997. The trophic ecology of freshwater 
Gammarus spp. (Crustacea: Amphipoda): problems and perspectives concerning the functional feeding group concept. Biol. Rev. 72: 349-364.

MacNeil, C., N. J. Fielding, K. D. Hume, J. T. A. Dick, R. W. Elwood, M. J. Hatcher, and A. M. Dunn. 2003. Parasite altered micro-distribution of Gammarus pulex (Crustacea: Amphipoda). Int. J. Parasitol. 33: 57-64.

Marcogliese, D. J. 2001. Implications of climate change for parasitism of animals in the aquatic environment. Can. J. Zool. 79: 1331-1352.

Médoc, V., C. Piscart, C. Maazouzi, L. Simon, and J.-N. Beisel. 2011. Parasite-induced changes in the diet of a freshwater amphipod: field and laboratory evidence. Parasitology 138: 537-46.

Médoc, V., T. Rigaud, L. Bollache, and J.-N. Beisel. 2009. A manipulative parasite increasing an antipredator response decreases its vulnerability to a nonhost predator. Anim. Behav. 77: 1235-1241.

Moenickes, S., A.-K. Schneider, L. Mühle, L. Rohe, O. Richter, and F. Suhling. 2011. From population-level effects to individual response: modelling temperature dependence in Gammarus pulex. J. Exp. Biol. 214: 3678-3687.

Moore, J. 2002. Parasites and the Behavior of Animals. Oxford University Press, New York.

Muzzall, P. M., and F. C. Rabalais. 1975. Studies on Acanthocephalus jacksoni Bullock, 1962 (Acanthocephala: Echinorhynchidae). I. Seasonal periodicity and new host records. Proc. Helminthol. Soc. Wash. 42: 31-34.

Olson, R. E., and I. Pratt. 1971. The life cycle and larval development of Echinorhynchus lageniformis Ekbaum, 1938 (Acanthocephala: Echinorhynchidae). J. Parasitol. 57: 143149. 
Perrot-Minnot, M.-J. 2004. Larval morphology, genetic divergence, and contrasting levels of host manipulation between forms of Pomphorhynchus laevis (Acanthocephala). Int. J. Parasitol. 34: 45-54.

Perrot-Minnot, M.-J., N. Kaldonski, and F. Cézilly. 2007. Increased susceptibility to predation and altered anti-predator behaviour in an acanthocephalan-infected amphipod. Int. J. Parasitol. 37: 645-651.

Perrot-Minnot, M.-J., M. Maddaleno, A. Balourdet, and F. Cézilly. 2012. Host manipulation revisited: no evidence for a causal link between altered photophobia and increased trophic transmission of amphipods infected with acanthocephalans. Funct. Ecol. 26: 1007-1014.

Perrot-Minnot, M.-J., M. Maddaleno, and F. Cézilly. 2015. Parasite-induced inversion of geotaxis in a freshwater amphipod: a role for anaerobic metabolism? Funct. Ecol. 30: 780-788.

Perrot-Minnot, M.-J., K. Sanchez-Thirion, and F. Cézilly. 2014. Multidimensionality in host manipulation mimicked by serotonin injection. Proc. R. Soc. B Biol. Sci. 281: 20141915.

Piscart, C., R. Genoel, S. Doledec, E. Chauvet, and P. Marmonier. 2009. Effects of intense agricultural practices on heterotrophic processes in streams. Environ. Pollut. 157: 1011-1018.

Pöckl, M., and U. H. Humpesch. 1990. Intra- and inter-specific variations in egg survival and brood development time for Austrian populations of Gammarus fossarum and G. roeseli (Crustacea: Amphipoda). Freshw. Biol. 23: 441-455.

Pöckl, M., B. W. Webb, and D. W. Sutcliffe. 2003. Life history and reproductive capacity of 

Gammarus fossarum and G . roeseli (Crustacea: Amphipoda) under naturally fluctuating water temperatures: a simulation study. Freshw. Biol. 48: 53-66.

Poulin, R. 1993. Age-dependent effects of parasites on anti-predator responses in two New Zealand freshwater fish. Oecologia 96: 431-438.

Poulin, R., and S. Morand. 2000. The diversity of parasites. Q. Rev. Biol. 75: 277-293.

Poulin, R., and F. Thomas. 1999. Phenotypic variability induced by parasites: extent and evolutionary implications. Parasitol. Today 15: 28-32.

Rosenblatt, A. E., and O. J. Schmitz. 2014. Interactive effects of multiple climate change variables on trophic interactions: a meta-analysis. Clim. Chang. Reponses 1: 1-10.

Roux, C., and A. L. Roux. 1967. Température et métabolisme respiratoire d'espèces sympatriques de gammares du groupe pulex (Crustacés, Amphipodes). Ann. Limnol. 3: 3-16.

Rumpus, A. E., and C. R. Kennedy. 1974. The effect of the acanthocephalan Pomphorhynchus laevis upon the respiration of its intermediate host, Gammarus pulex. Parasitology 68: 271-284.

Sato, T., T. Egusa, K. Fukushima, T. Oda, N. Ohte, N. Tokuchi, K. Watanabe, M. Kanaiwa, I. Murakami, and K. D. Lafferty. 2012. Nematomorph parasites indirectly alter the food web and ecosystem function of streams through behavioural manipulation of their cricket hosts. Ecol. Lett. 15: 786-793.

Sheath, D. J., D. Andreou, and J. R. Britton. 2016. Interactions of warming and exposure affect susceptibility to parasite infection in a temperate fish species. Parasitology 143: $1340-1346$.

Stefano, G. B., and E. J. Catapane. 1977. The effects of temperature acclimation on 
monoamine metabolism. J. Pharmacol. Exp. Ther. 203: 449-456.

581

582

583

584

585

586

587

588

589

590

591

592

593

594

595

596

597

598

599

600

601

602

Stefano, G. B., L. Hirtpi, and E. J. Catapane. 1977. The effects of short and long term temperature stress on serotonin, dopamine and norepinephrine concentrations in molluscan ganglia. J. Therm. Biol. 3: 79-83.

Tain, L., M.-J. Perrot-Minnot, and F. Cézilly. 2006. Altered host behaviour and brain serotonergic activity caused by acanthocephalans: evidence for specificity. Proc. Biol. Sci. 273: 3039-45.

Tain, L., M.-J. Perrot-Minnot, and F. Cézilly. 2007. Differential influence of Pomphorhynchus laevis (Acanthocephala) on brain serotonergic activity in two congeneric host species. Biol. Lett. 3: 68-71.

Thomas, F., J. Brodeur, F. Maure, N. Franceschi, S. Blanchet, and T. Rigaud. 2011. Intraspecific variability in host manipulation by parasites. Infect. Genet. Evol. 11: 262269.

Thomas, F., S. P. Brown, M. V. K. Sukhdeo, and F. Renaud. 2002. Understanding parasite strategies: a state-dependent approach? Trends Parasitol. 18: 387-390.

Thomas, F., R. Poulin, T. De Meeûs, J. Guégan, and F. Renaud. 1999. Parasites and ecosystem engineering: what roles could they play? Oikos 84: 167-171.

Thomas, F., F. Renaud, T. De Meeûs, and R. Poulin. 1998. Manipulation of host behaviour by parasites: ecosystem engineering in the intertidal zone? Proc. R. Soc. B Biol. Sci. 265: 1091-1096.

Tokeson, J. P. E., and J. C. Holmes. 1982. The effects of temperature and oxygen on the development of Polymorphus marilis (Acanthocephala) in Gammarus lacustris (Amphipoda). J. Parasitol. 68: 112-119. 

and species interactions in terrestrial ecosystems. Ecol. Lett. 11: 1351-1363.

Van Cleave, H. J. 1916. Seasonal distribution of some acanthocephala from fresh-water hosts. J. Parasitol. 2: 106-110. 


\section{Tables}

609 Table 1. Correlations (Spearman's rho) between phototaxis and refuge use scores in control

610 and parasitized $G$. fossarum, at each temperature $\left(10,14\right.$, and $\left.18^{\circ} \mathrm{C}\right)$.

\begin{tabular}{|c|c|c|c|}
\hline Infection status & Temperature & Spearman’s rho & $P$ \\
\hline \multirow[t]{3}{*}{ Control } & $10^{\circ} \mathrm{C}$ & -0.167 & 0.344 \\
\hline & $14^{\circ} \mathrm{C}$ & -0.310 & 0.124 \\
\hline & $18^{\circ} \mathrm{C}$ & -0.053 & 0.743 \\
\hline \multirow[t]{3}{*}{ Parasitized } & $10^{\circ} \mathrm{C}$ & -0.017 & 0.936 \\
\hline & $14^{\circ} \mathrm{C}$ & -0.186 & 0.432 \\
\hline & $18^{\circ} \mathrm{C}$ & -0.416 & $0.020^{1}$ \\
\hline
\end{tabular}

611

${ }^{1}$ non-significant after Bonferroni correction

612

613 
615 Figure 1. Individual Gammarus fossarum behavior scores for (A) phototaxis tests and (B) 616 refuge use tests, according to their infection status ( $\mathrm{P}$ or C, respectively parasitized by $P$.

617 618 tereticollis or control) and temperature $\left(10,14\right.$, or $\left.18^{\circ} \mathrm{C}\right)$. Thick lines represent medians, boxes represent upper and lower quartiles, and dotted lines represent upper and lower deciles. Sample sizes are indicated at the bottom of the graph.

Figure 2. Effect sizes (Cliff's delta, d) of the behavioral differences (A) between temperatures, for each test and each infection status (parasitized and control), and (B) between parasitized and control G. fossarum individuals, for each test (phototaxis, refuge use, and geotaxis) at each temperature $\left(10,14\right.$, and $\left.18^{\circ} \mathrm{C}\right)$. Cliff's delta effect sizes are represented with their 95\% confidence intervals, and their values are given. Values below zero (dotted line) indicate that the behavioral score was higher for the group specified on the left, while values above zero indicate higher scores for the group mentioned on the right. The difference is significant when the bar does not overlap zero. For instance, the first row indicates that phototaxis scores of control individuals were significantly higher at $14^{\circ} \mathrm{C}$ compared to $10^{\circ} \mathrm{C}$.

Figure 3. Individual Gammarus fossarum geotaxis scores according to their infection status (P or C, respectively parasitized by $P$. minutus at the cystacanth stage, or control) and temperature $\left(14\right.$ or $\left.18^{\circ} \mathrm{C}\right)$. Thick lines represent medians, boxes represent upper and lower quartiles, and dotted lines represent upper and lower deciles. Sample sizes are indicated at the bottom of the graph. 

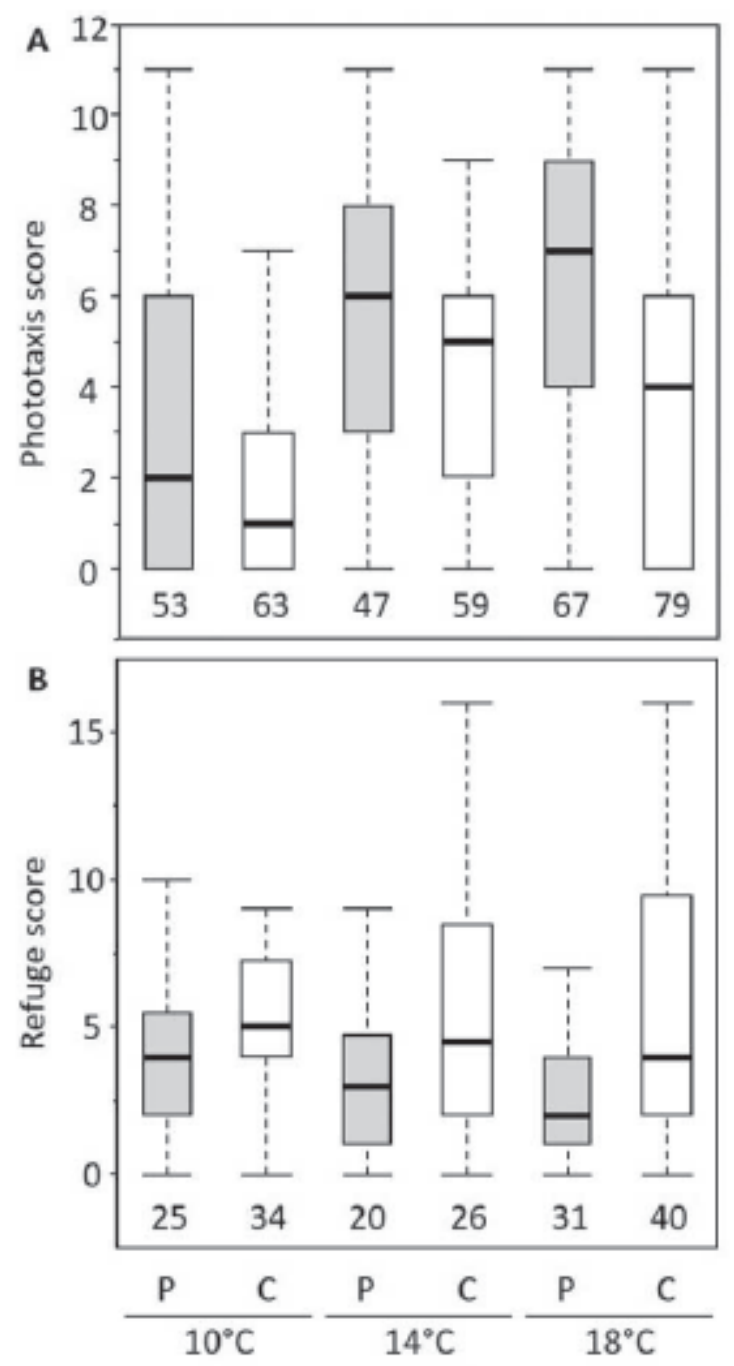

Temperature and infection status

Figure 1 
A. Comparisons between temperatures

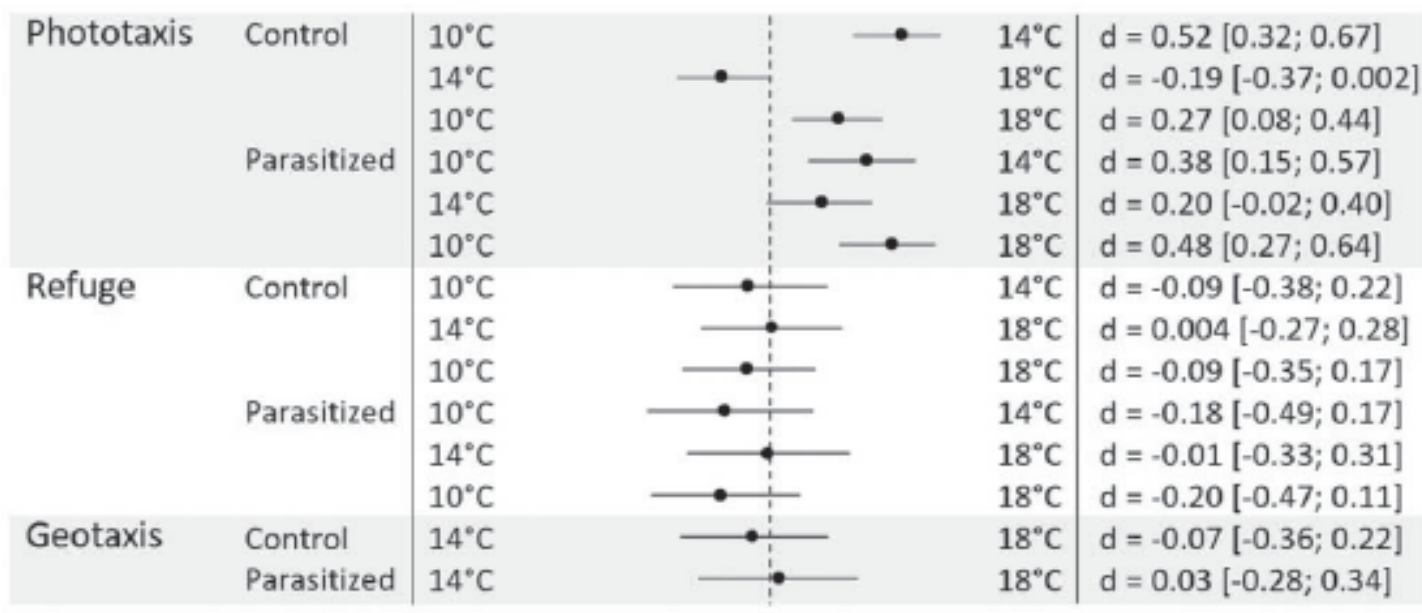

B. Comparisons between control and parasitized individuals

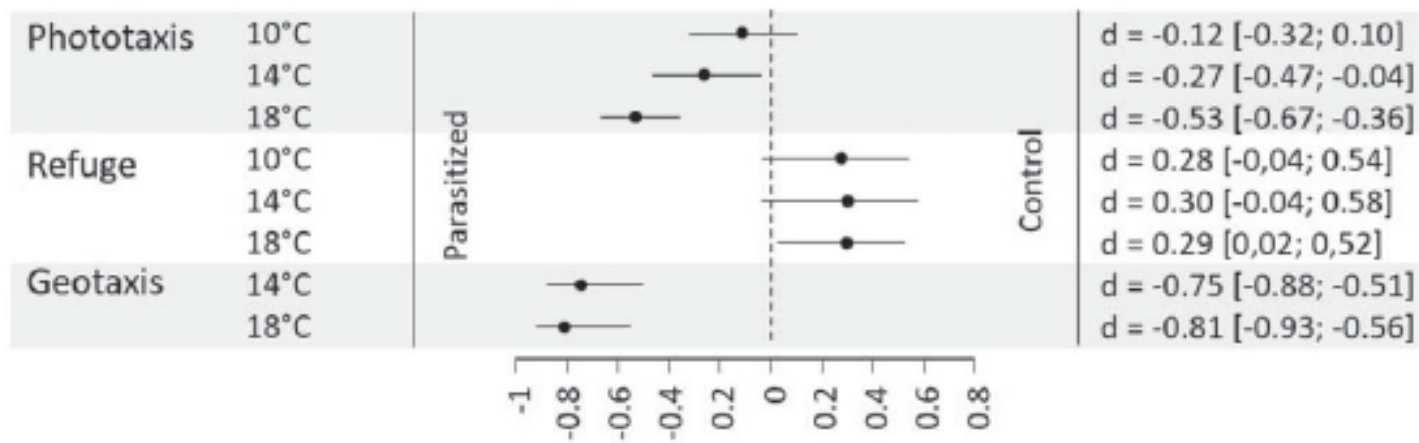

Figure 2 


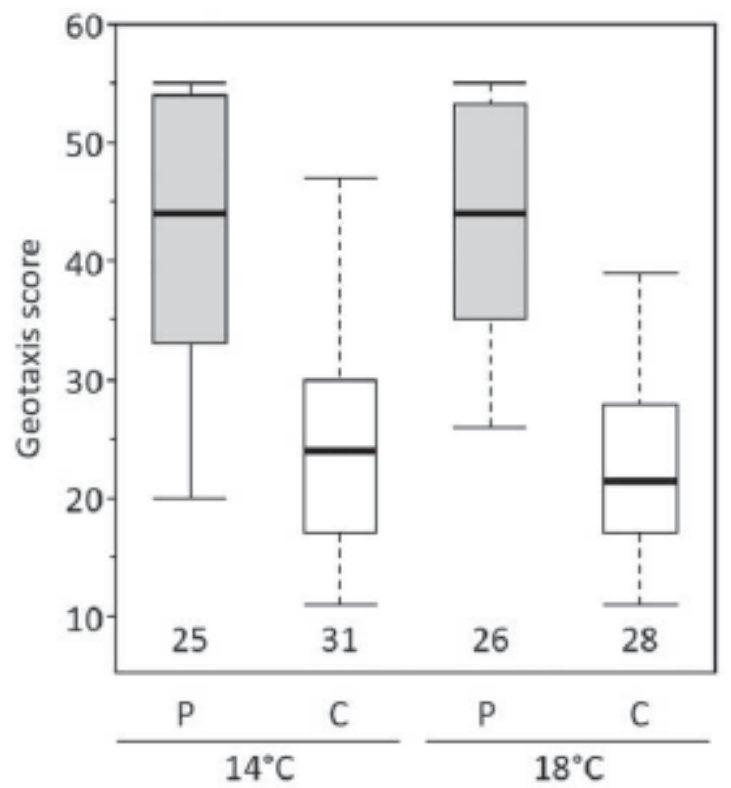

Temperature and infection status

Figure 3 